\begin{tabular}{|c|c|} 
European Association for the & $\begin{array}{c}\text { International Conference on Renewable Energies and Power Quality } \\
\text { (ICREPQ'12) }\end{array}$ \\
$\begin{array}{c}\text { Development of Renewable Energies, Environment } \\
\text { and Power Quality (EA4EPQ) }\end{array}$ & Santiago de Compostela (Spain), 28th to 30th March, 2012
\end{tabular}

\title{
Reimbursement Procedure due to Electrical Damages: the Subject Relevance, Juridical Fundamentals, Agency Standards, Analysis Procedures and Trends
}

\author{
I. N. Gondim¹, P. H. O. Rezende¹, J. C. Oliveira'1, J.R.Macedo Jr¹ ${ }^{1}$ A. C. O. Salomão², N. Kagan² \\ ${ }^{1}$ Federal University of Uberlandia, Faculty of Electrical Engineering, Av. João Naves de Ávila, 2121 - Campus Santa \\ Mônica, Bloco 3N, CEP:38402-902, Uberlândia, MG - Brazil, Phone: +55 3432394763 /+55 3432394733 \\ ${ }^{2}$ University of São Paulo, Polytechnic School, Department of Power Engineering and Electrical Automation, Av. Prof. \\ Luciano Gualberto, Trav. 3, n. 158, CEP: 05508-900, São Paulo, SP - Brazil, Phone: +55 1130915473
}

\begin{abstract}
This article, associated with the Brazilian experience, aims at making considerations on issues linked with the process involving general consumer appliances damages apparently attributed to abnormal supply by the electric grid. The paper highlights today's trends and the relevance of the subject, the legal fundamentals that has guided the matter, the regulatory procedures established by the national agency with emphasis in the focused matter, the traditional mechanisms to achieve the utility final report about the request consistence. Discussions are carried out about the possibilities that are open to achieve a more reliable manner of producing the final answer to a specific request. The work highlights the weaknesses of the strategies currently used to provide the analysis in practice and presents the fundamentals of methodologies based on scientific principles and techniques that are expected to fulfill the law and regulation obligation. The proposed approaches attempt to provide a more impartial and agile procedure keeping in mind the search for a consistent way to recognize the causal link between the allegedly manifested disturbances in electrical grids and the claims made by consumers.
\end{abstract}

\section{Key words.}

Reimbursement, Electrical damage, Refunding process, Computational approach, Consumer rights

\section{Introduction}

The large number of demands associated with consumer reimbursement due to electrical appliance damage has, in recent years, been the focus of growing concerns by electric utilities, regulatory agencies, consumers and other government agencies. Such worries are associated not only with the financial stakes involved, but mainly with the social impacts linked with requests, decisions, conflicts and other issues involving the relationship between utilities and their customers. Therefore, the issue, as a whole, has motivated researches to investigate the fragilities of existing methods and search for proposals of new approaches to cope with the matter. In general, the analysis comprises a procedure based on the relationship between a given damaged product claimed by the final user and the simultaneous occurrence of an abnormal operational condition in the transmission or distribution network, i.e., the correlation between disturbances and effects [1]. This particular field of research, in addition to the attempt of producing a more consistent tool to provide the final answer to a specific request, also helps in the establishment of guidelines for the offering of products with a withstand capability, in terms of dielectric and thermal limits, compatible with typical disturbances in electrical networks [2], [3].

Seeking reimbursements to the matter at hand, one of the probable causes for conflict is rooted in the guidelines of ANEEL (Brazilian Electricity Regulatory Agency). These are based on experience and common sense to sort out the conflict and, in general terms, if there is an abnormal system occurrence coinciding with equipment damage in the neighborhood, then the refunding must be done. In fact, the agreement or disagreement of the requests sent for analysis becomes extremely difficult, leaving the utilities with the only possibility of checking the causality and severity of impacts produced by the event occurred on the products claimed. This way, it is quite clear that the commonly used method does not find support in any scientific or technical principles and, faced with this situation, there are often misunderstandings and dissatisfaction regarding the final advice.

Keeping in mind the achievement of a consistent evaluation processes to be utilized to the subject of reimbursement in a fair and cohesive way, one could imagine that by reproducing the recognized phenomenon manifested on the utility responsible for the supplier with the dielectric and thermal tolerances admissible by the claimed product, it is possible to have a relationship between the input efforts in the product voltage and current limits.

From the above argument emerges the idea of developing systematic procedures based on the balance between the use of computational resources linked to laboratory tests, which, when combined, can produce reliable tools to guide decisions regarding the utilities requests for recovery of damages. In doing so, it is believed that a new manner of providing a final, fair, and coherent answer to the matter here focused is possible. This approach would certainly lead to a final report that would be more consistent, reliable and with no tendency in favor of the utility or the consumer. Besides the above, the agility of providing a reply to a given consumer request and the technical and scientific fundamentals 
supporting the procedure would result in savings, less conflict and a smaller number of litigations.

Within this context, this paper has the purpose of enhancing the relevance of the focused issue throughout the exemplification of the Brazilian statistic related to the number of refunding request over the past year, and it also shows some figures to illustrate the problem for a specific utility comprising a small part of its overall distribution area. Then, the juridical fundaments associated to the consumer rights are considered, as well as the guidelines to support the subject as defined by the Brazilian Electric Energy Agency. Once the analyses procedure is pointed out, further discussions are carried to highlight the current process and its fragilities. Finally, the results describing procedures to claim refunds based on computational programs to cope with the disturbing phenomenon impact upon the appliances are presented in order to overcome the referred matter.

\section{Qualitative and quantitative considerations about reimbursements}

In order to provide general information on the subject in focus, this section is directed to a characterization of the relevance of the matter within the Brazilian context. This way, it is noteworthy to point out that the results summarized here express qualitative and quantitative magnitudes related to compensation claims all over the country over the year of 2010. In addition, specific information linked to a particular distribution utility is given to complement the overall view of the subject here considered. This way, the most relevant appliances claimed are shown as well as the growing rate of the reimbursement requests for this specific concessionary.

Figure 1 expresses numbers collected by the Brazilian Agency for Regulating the Distribution of Electrical Energy - ANEEL and which are associated with 18 utilities out of a total number of 64 distribution companies. The chosen ones reflect the highest number of requests received; therefore, the numbers are incomplete and represent the situation experienced during the year 2010 by only $30 \%$ of national companies. The importance of the topic and its relevance to stakeholders, namely consumers, utilities and regulatory agency, related to the figures involved shows that the problem is quite latent. In fact, by adding the numbers informed, which do not represent the total requests, it has been found around 260,000 complaints of claims, of which approximately $45 \%$ were upheld and 55\% rejected.

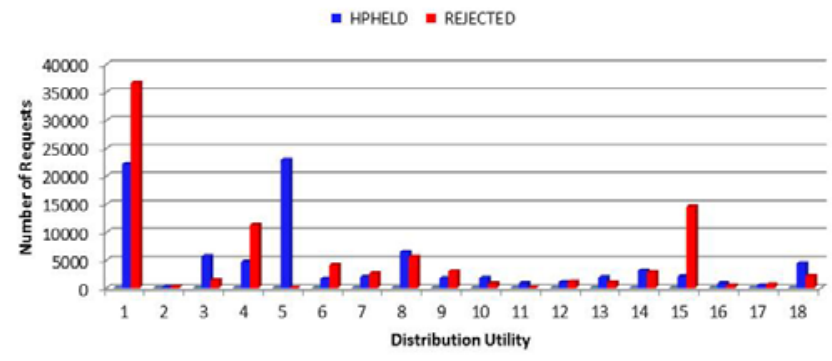

Fig. 1. A sample of the number of claims for electrical damage over the year of 2010 in 18 distribution companies.
So as to highlight the most claimed refund type of products, Figure 2 illustrates an statistic result for a given distribution concessionary responsible for the electrical energy supply in one of the most populated state of the country. The data comprises claims that have been considered consistent, and thus the reimbursement was approved. The diversity of products is evident and the majority involves appliances with relatively high costs. Due to this, an average amount of $€ 150$ could be considered as a typical value applied to an individual consumer that has been granted with the refunding process.

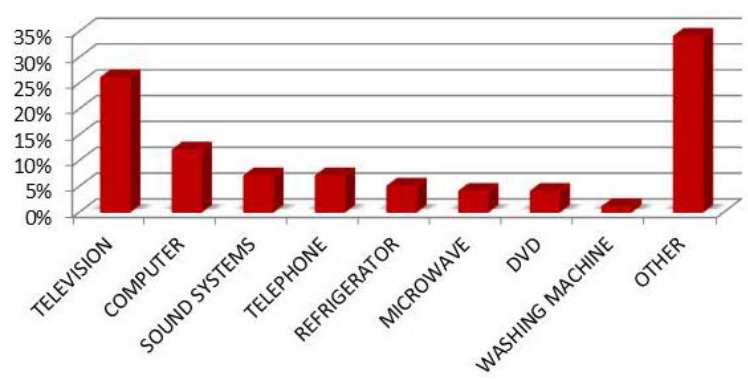

Fig. 2. Statistical result of the most common appliances focused in the reimbursement process for a specific distribution utility.

In accordance with the above, cost associated to each process and by taking into account the number of equipment hypothetically damaged by abnormal operating conditions of the power system distribution, Figure 3 shows, for the chosen particular concessionary, the total financial values paid during the period of four years. Again, it is evident that the figures are significant in both absolute values as well as in terms of the growth rate of compensation. As a matter of fact, the focused topic has been found to be increasing in an exponential way. These arguments reflect the clear and unambiguous relevance of the issue and the importance of seeking legal and technical mechanisms to provide more consistent procedures to cope with the subject until the final answer is given to a specific request.

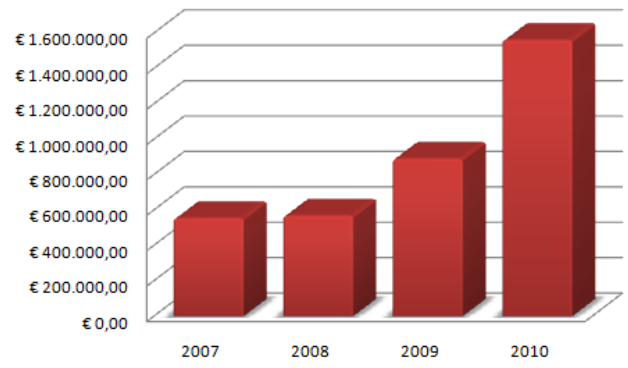

Fig. 3. Total costs reimbursed for claims for damages - example applies to the same distribution company in the previous figure.

In terms of the possible reason for the occurrence, Figure 4 shows the practical possibilities of the alleged events which would be linked, in most cases, to compensation claims. This figure has been supplied by the same utility that has supplied the data expressed in figures 2 and 3. As it can be seen, the lightning and the automatic reclosing are found to be the main causes of complaints. Despite this, the simple presence of a specified phenomenon occurrence must yet been considered in 
terms of its voltage and current values and the corresponding duration. Therefore, a single disturbance manifestation cannot be responsible for the final damage claimed. This, however, has not been considered by the regulation as it will be later considered.

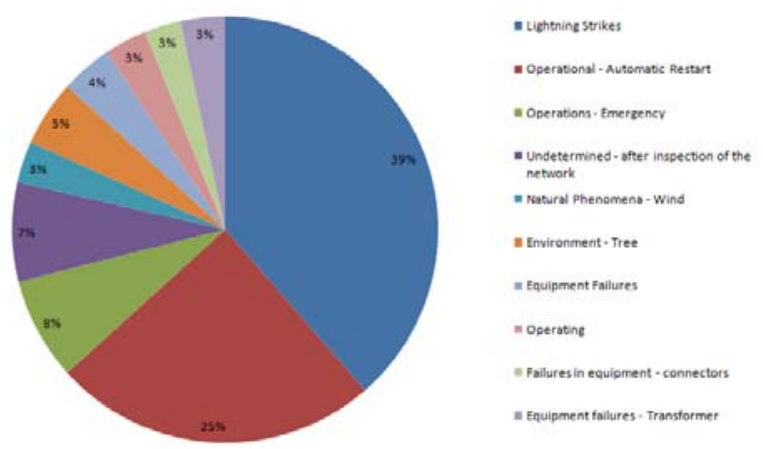

Fig. 4. The main abnormal operating conditions identified by the distribution utility responsible for the numbers given in previous figures.

\section{Legal approach}

The electrical power is considered an essential service and, as provided by law, it should be offered properly and with quality. Based on this assumption and, in accordance with the current legal system, especially the Federal Constitution precepts, there is no doubt that the legal entities with private rights in charge of public services, such as electrical power supply companies, will be liable for damages caused to others. This way, it is clear that private companies, when they are assigned the duty of executing the public interest services, whether through concession, permit, or authorization, are liable for damage caused by the failure of services. As stated by [4] "Who has the bonus must bear the onus", conduct to "one who participates in the Public Administration, which provides public services, enjoying the benefits of this activity, should support its risks, be liable in equality with the State, in whose name it operates".

Although the knowledge given in [5] establishes that the public service user is not a consumer as far as the juridical point of view is concerned, it is adopted, for the present study, the position that the users not being provided by public service of a specific legislation to ensure and support their rights and obligations, and also considering that the Consumer Protection Law is in accordance with the Federal Constitution as expected, one should appeal to the implementation of the legislation in the relationship verified between the legal entities of private rights, providers of public services, and their users. Moreover, it is worthwhile to notice that the rules applied by the Consumer Protection Law are of public order and social interest, and thereby they are to guide the basic values of a society, being this way, a mandatory compliance. It's of essential weigh that this consumer legislation takes a strict liability, under which it is dispensed the evidence of guilt to achieve the duty to reimburse.

As found in [6] "in face of this trend, the legislature actually came to contemplate the consumer law application for the public services", but it has been warned by the author that this: "however, cannot lead to its indiscriminate application ". So, based in this assumption, it follows that the consumer legislation has been applied to relations involving public services users, including those cases involving damage to the user due to the public power supply. This knowledge has been verified by repeated decisions from courts.

Finally, it should not be forgotten the electricity regulatory agency (ANEEL) role at mitigating the problems existing between concessionaries and their users. Indeed, beyond the regulatory and surveillance tasks assigned by law, this body has the competence to emit the necessary actions to comply with the standards established by the legislation. Thus, in resolving conflicts between public services users and the utilities, it is important to note that disposed by the Resolutions issued by ANEEL, which should be in perfect harmony with the provisions of the Consumer Protection Law and, especially, in concordance with the Federal Constitution provisions, taking to account the hierarchy of standards existing in the hierarchical arrangement of the legal rules, this agency has produced guidelines to support the matter under consideration.

However, although the evidence of the responsibility is not necessary, in order to attribute the concessionary obligation at reimbursing the electrical damage caused to consumers, it is essential the realization of some assumptions, such as: the effective damage caused to the consumer; the unlawful act, based in the act or omission by the agent causing the damage that infringes the rights and causes injury to others and, finally, the causal nexus between the occurrence and the damage practiced.

This way, it is worthwhile to point out that, for specific situations, the public administration and public service providers may be suppressed in refunding the claimer, even though there is the occurrence of damages to others, in cases where there may exist some rejection of civil responsibility. Therefore, in those situations in which may exist the incidence of some rejection of civil responsibility, noting the absence of a causal nexus between the damage caused to the consumer and any failure or service deficiency by the power company, there is no reason for refunding by the utility.

Finally, it is important to emphasize that although the current legislation sustains the consumers right to their reimbursing due to any electrical damage caused by failure or defect in the public power supply, there are difficulties faced by consumers in obtaining their rights. On the other hand, the consumers total ignorance in situations in which they would be against some rejection of responsibility of the power company, therefore existing no obligation by the utility to proceed with the claims, leads to believe that it is urgent a standard of procedures used in the refunding request analysis for electrical damage. This points out to the need of having standards through mechanisms or software based in the technical and scientific analysis, which is able to measure more accurately if it really exists a causal nexus between the disturbance in the electrical system and the damage caused to the consumer. 


\section{Resolutions of the regulatory agency}

As a result of the above issues and others, especially regarding the rights of consumers as predicted by the services offered, it is recognized that the standardization of rules for the reimbursement process analysis is a matter of great importance. In this direction, both the Brazilian Electricity Regulatory Agency (ANEEL) and the National System Operator (ONS) have produced guiding documents on the normalization of the patterns of electricity supply, the Distribution Procedures [7], and Network Procedures [8].

Focusing specifically on the issue of damages and requests for reimbursement, the Normative Resolution 61, April 29, 2004 - ANEEL, amended by the Normative Resolution 360 of April 14, 2009 [9], are the main documents to support the focused subject. These set out the provisions relating to refunding of damages for electrical equipment installed in consumer units, caused by disturbance occurred in the system supply. In these resolutions, it appears that the procedures adopted are bound only to causation, which is defined as the bond that determines the causal link between the distribution network event and the damage claimed. The Article 5 of the above documents is transcribed below:

"Article 5 - In the processing of the request for reimbursement, the distributor shall investigate the existence of a causal nexus, considering the records of occurrences in its network"

In addition to the normative resolutions presented, in the later months, the above legislation has been reviewed. This way, a public audience has been promoted by the Regulatory Agency of the electricity sector (public consultation No. 34 of 06.27.2011). The main idea is to gather contributions for the approval of the Distribution Procedures in its Module 9. This text comprises new orientation to the processes of reimbursement analysis due to electrical damage. This is a work that still is been carried out in the country.

\section{Procedures for issuing final reports on requests for reimbursements}

\subsection{Procedure in use}

The criteria and procedures for the evaluation of requests for reimbursement are based on current legislation as previously stated. The process comprises two steps of evaluation: administrative and technical procedures.

\section{A. Administrative Procedures:}

The administrative procedures are associated to the supply of the necessary documentation, forms, and others. This is made by the consumer at the utility office and the overall process starts as soon as these requirements are fulfilled. The main information to be given are:
- The claimed equipment invoice or statement signed that the claimer is the owner of the damaged equipment;

- A statement about the date and time at which the failure has occurred;

- The technical report given by an authorized repair workshop stating the damage and the cost for repairing the appliance.

Moreover, the distribution company is obliged, within 30 days, to evaluate and give the final answer to the consumer. For special products such as refrigerators or others this period is reduced to 48 hours.

\section{B. Technical Procedures}

Once the above requirements have been completed, the technical analysis is started. The target is to check the information with emphasis to the evidence of a real causal nexus so as to unequivocally finds if the damages claimed are consistent with the system disturbance.

In addition, an inspection may be required at the scene, and, if this occurs, a complete report is to be made identifying the consumer unit, the electrical feeder from the medium voltage until the end consumer, and other relevant information. It may still be carried out a visual inspection of the consumer unit claimant to verify the compliance of facilities with the technical standards of the utility and technical standards of electrical installations in the country. Finally, the process may further comprise an overall assessment of the product with respect to its power, voltage, brand, type, year of manufacture, existing protection, and physical conditions in which it lies.

Figure 5 represents the flow chart summarizing such process.

By following the above, it becomes quite clear that the process as a whole is strongly dependent on the person point of view and no technical or scientific basis have been taken into account. This reveals that the procedure may show a great fragility as the mechanisms are entirely based on empirical experience as a whole.

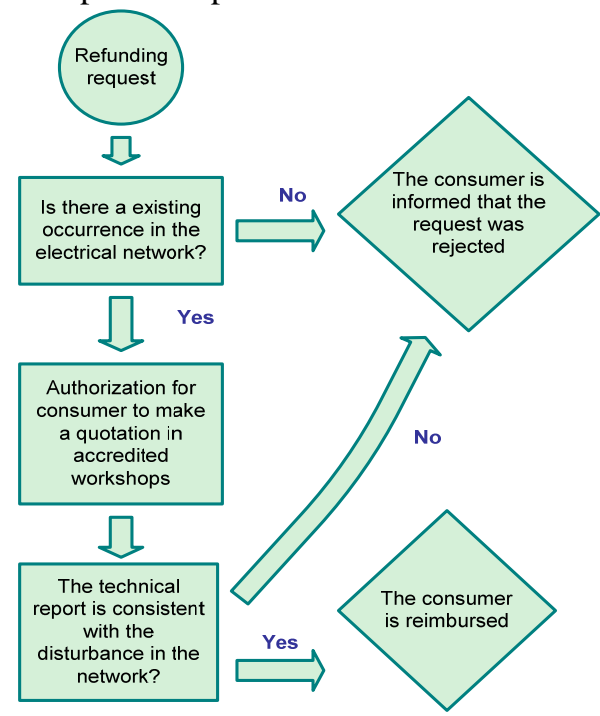

Fig. 5. Flowchart of the steps associated with the process of technical analysis applications for the refund of claims. 


\subsection{Procedures proposals to the reimbursement consistence analysis}

Recognizing the limitations linked with the mechanisms described above and in line with the new guidelines proposed by the regulator, the development of more reliable means of analysis, based on scientific principles and technical fundamentals have motivated the interest of researches. As far as for the Brazilian context, it is recognized, actually, two products arising from research and development projects. These are summarized in the sequence.

\subsubsection{Reimbursement Computational Program Analysis by Federal University of Uberlandia}

Through a series of studies conducted at the Federal University of Uberlandia, a very comprehensive software was obtained and nominated by Applicative to Reimbursement Decision (APR) [10]. It uses a program to promote a friendly interface between the network configuration of the disturbances and with the ATP software (Alternative Transients Program). Figure 6 shows the structure of the program and shows, in summary, the functions performed by the product.

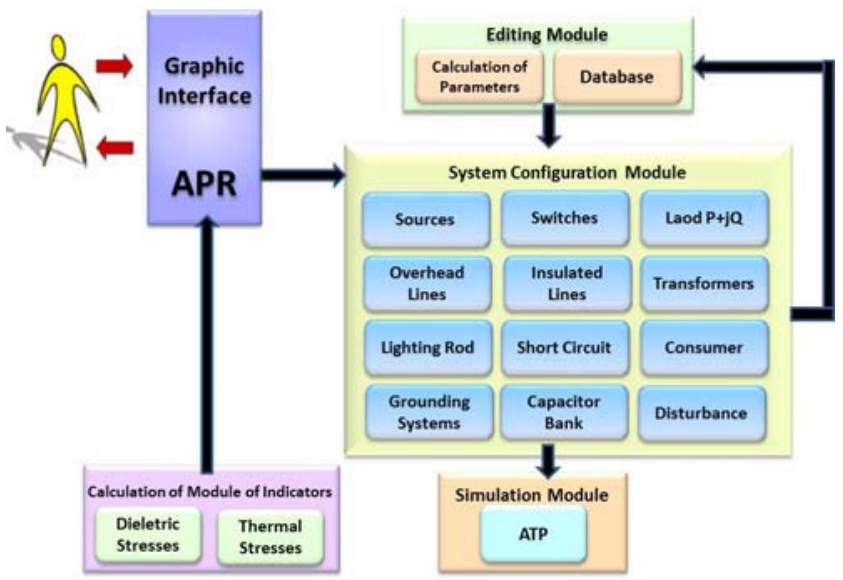

Fig. 6. Structure of the APR software.

In essence, the computational resource in question seeks to reproduce, spread, and correlate feasible to demonstrate the disturbances in electrical networks and their impact on equipment fed by feeders, distribution, or others. In this sense, events such as: lightning, short circuits, operation of protection devices, several maneuvers, etc. can be achieved through a basic and solid computational program, which is widely accepted by electric power companies in Brazil and the world. Alternatively, information associated with direct measurements can also be used to characterize the anomaly that occurs in the network. Finally, the impacts of the phenomena are propagated to the point of consumer connection where the complainant damaged equipments are represented by models supported by each product concerned. By correlating the voltage and current incidents in terms of dielectric and thermal efforts, it is then possible, by comparing these requests with the standards supporting the devices, verify the existence or not of a causal connection and the issue of a conclusive ruling on the request made. Figure 7 illustrates the application interface for a typical situation.

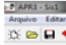

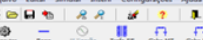

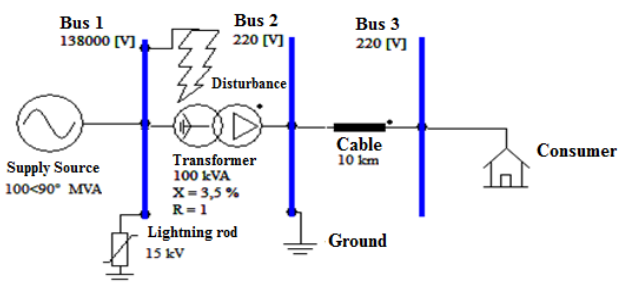

Fig. 7. Example of the use of the APR software.

By way of illustration, Figure 8 shows the result of analysis conducted for a particular situation related to a claim of a stereo appliance, supposedly attributed to an incidence of lightning. For the case in question, the level of dielectric stress exceeded the tolerance limits of the equipment in large proportions, a fact which would indicate the burning of the equipment.

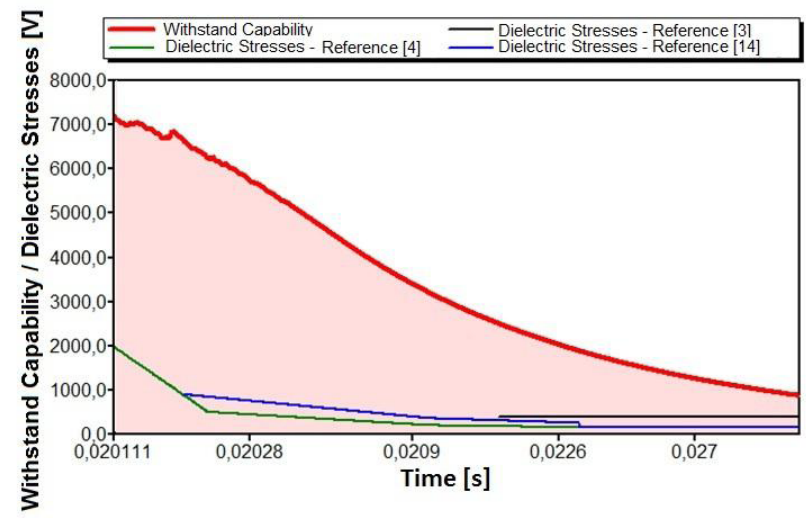

Fig. 8. Illustration of the results of a computational study on a request for reimbursement

\subsubsection{Reimbursement Procedure by University of Sao Paulo}

The tool developed by the University of Sao Paulo, obtained through studies conducted by ENERQ - Center for Regulation and Power Quality [12, 13], incorporates a system for consulting the databases of companies to access the network occurrences and identify signs of situations that may have caused disturbances that are potentially assignable to damage equipments. If effected, then there is the analysis of the possibility of damage due in function of the power supply to the consumer, type of equipment, and its susceptibility to disturbances. The general structure of the review program is shown in Figure 9. This procedure shows a line that begins with the request of the consumer, finding the existence of an anomaly of the operational supply network, identifying the nature of the phenomenon occurred, and, finally, a comparison is made between cause and effect. By this way, the structure includes a database involving the demands imposed on the level and properties and capability withstand for allowable products. 


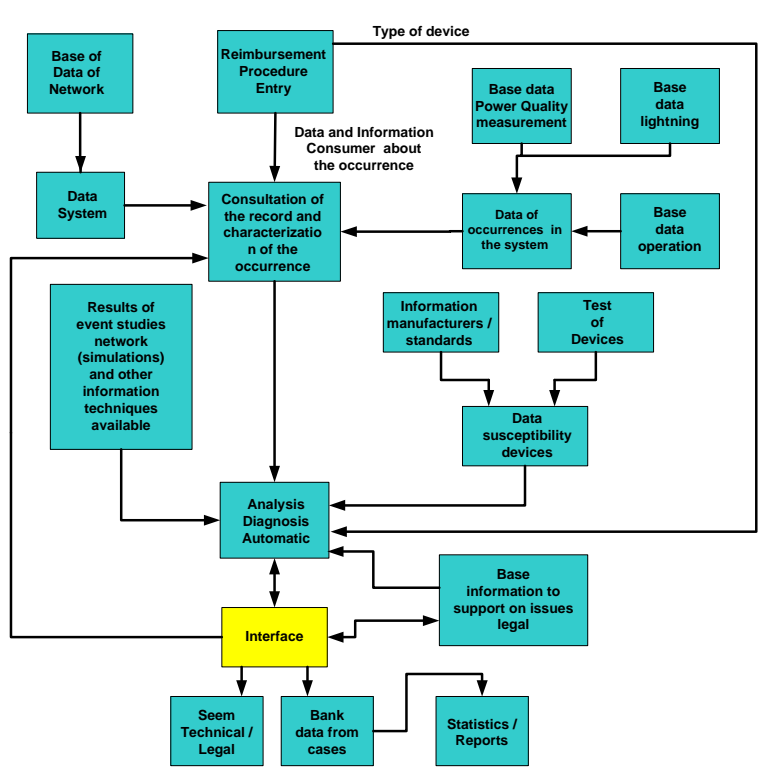

Fig. 9. General structure of the analysis strategy

The strategy includes a correlation between the type of disturbance on a particular device, considering the severity of the occurrence and susceptibility of the device in relation to this type of misoperation. Regarding the information linked with the manifestations of phenomena responsible for damages, it arises from the experiences of companies and the electricity sector in general, thus forming a database that enables the characterization of events as to their origin and values. The limits of product capability withstand in the studies considered are drawn from studies performed in a high-voltage laboratory. Confronting efforts to admissible levels for the equipment is thereby, established as a mechanism for finding a causal link or not.

\section{Conclusion}

This paper has focused on the subject of consumer claims for electrical damages. This topic has been found to be growing in number and values, and the search for consistent ways of producing final reports about the causal nexus between system occurrences and appliances damages has been highlighted. Although the authors recognize the existence of specific publications on the subject, the correlation between the different topics linked with issues involving the legal, standards, and methods of analysis are linked, and the problems should therefore be treated within this perspective, and a first trial has been done in a comprehensive way. Focusing specifically on the methods of analysis of claims, it was found evident that, currently, the matter is still treated in an empirical manner which, inevitably, can lead to erroneous opinions on the decision-making processes. Given this, the article highlighted two strategies based on classically accepted principles and computer programs. Through the analysis methods presented, it was shown that the proposed techniques aims to search for effective mechanisms and consistency in expediting the process of analysis of the causal claims formulated for electrical damage and, therefore, in issuing reasoned opinions on a solid foundation of engineering.

\section{Acknowledgement}

The authors acknowledge the financial support received from Brazilian Councils FAPEMIG, CAPES, and CNPq for the doctorate and master scholarship which resulted in this paper.

\section{References}

[1] R. C. Dugan, M. F. McGranaghan, S. Santoso, H. W. Beaty, Electrical Power Systems Quality, 2nd Edition, USA: McGrawHill, 2003.

[2]M. H. J. Bollen, Understanding Power Quality Problems: Voltage Sags and Interruptions, Piscataway, IEEE Presss, 2000. [3]K. Ermeler, W. Pfeiffer, D. Schoen, M. Schocke, "Surge Immunity of Electronic Equipment", IEEE - Electrical Insulation Magazine, Vol. 14, 1998.

[4]Cavalieri Filho, Sérgio. Civil Responsibility Program, $9^{\text {th }}$ edition. São Paulo: Atlas, 2010. p. 257-in portuguese.

[5]Cintra do Amaral, Antônio Carlos. Public Service Concession. 2th. Edition, São Paulo: Malheiros EditorsLtd, 2002. p. 113 - in portuguese.

[6] Landau, Elena (Coord.). Electrical Power Grid Regulation. Rio de Janeiro: Lumen Juris Editor, 2006. p. 166 - in portuguese.

[7] ANEEL - Brazilian Electricity Regulatory Agency Standard 395, december 15th 2009 - in portuguese.

[8] ONS - Brazilian Grid Operator - Transmission Grid Performance Standard - module 2.2, december 2002 - in portuguese.

[9] ANEEL - Brazilian Agency of Electrical Energy - Standard 360, april 14th 2009 - in portuguese.

[10] Tavares, C. E., "A Computational Proposal to the Evaluation of Responsability Concerning ConsummerReimborsement due to Electrical Damages”, $\mathrm{PhD}$ thesis, Federal University of Uberlandia - Brazil - May 2008 in portuguese.

[11] Salomão, A. C. O., "The Juridical and Technical Aspects of Consumer Reimbursement due to Electrical Disturbances Damages in Electrical Appliances” - MSc Qualification, USP Brazil - march 2010 - in portuguese

[12] Kagan, N. ; Matsuo, M. N. ; Duarte, S. X. ; Itocazo, Fernando ; Domingues, I. T. . Assessing the risk of damages in low voltage equipment due to lightning surges and their impact on customer claims. In: CIRED - International Conference on Electricity Distribution, 2007, Viena. CIRED2007 International Conference on Electricity Distribution, 2007

[13] Kagan, N. ; Matsuo, N M ; Ferrari, e L ; Duarte, S X ; Penin, C. A. ; Domingues, I. T. ; Monteiro, A. J. . Methodology for Support and Analysis of Indemnity Requests due to Electrical Equipment Damaged in Eletropaulo Costumers. In: ICHQP - International Conference on Harmonics and Quality of Power, 2002, São Paulo. ICHQP - International Conference on Harmonics and Quality of Power, 2002. 